\title{
Dispersion of Human Capital and Economic Growth
}

\author{
Jungsoo Park* \\ Dept. of Economics \\ State University of New York at Buffalo
}

January 31, 2004

\begin{abstract}
Based on a theoretical consideration of human capital production technology, this study empirically investigates the growth implication of dispersion of population distribution in terms of educational attainment levels. Based on a pooled 5-year interval time-series data set of 94 developed and developing countries for 1960 to 1995, the study finds that dispersion index as well as average index of human capital positively influences productivity growth. Given limited social resources for human capital investment, the finding implies that education policy that creates more dispersion in the human capital will promote growth.
\end{abstract}

JEL Classification : O4, I2, J24

Keywords: Human capital, Dispersion, Educational attainment, Economic growth

\footnotetext{
* Jungsoo Park, Assistant Professor, Department of Economics, State University of New York at Buffalo, 415 Fronczak Hall, Buffalo, NY. 14260-1520. Phone 1-716-645-2121 x.440, Fax 1-716-645-2127, E-Mail jungsoo@buffalo.edu
} 


\section{INTRODUCTION}

Models of endogenous growth have pursued theoretical framework where persistent economic growth is conditioned on human capital accumulation, as in Lucas (1988) and Romer (1990). The implication of these models is that human capital is the driving force in the growth process of an economy. Barro (1991), Benhabib and Spiegel (1994), Dinopoulos and Thompson (2000), and many others find empirical evidence supporting these models, relating human capital with productivity growth. In these studies, human capital stocks are represented by average schooling years or enrollment ratio of the population which, however, may not appropriately reflect the actual capacity of aggregate human capital in an economy. It may well be that given the same average index of schooling, economies with different distributions of population in terms of educational attainment levels may perform differently.

Education policy and structure of social incentive system regarding human capital accumulation will determine the distribution of population across various educational attainment levels. It is interesting to note that not only the average schooling years but also distribution of population in terms of different educational attainment levels varies widely across economies and across time. For example, although both Canada and Norway have similar average schooling years for their population, Canada's population is vastly more diverse in terms of its individuals' educational attainment levels than that of Norway. ${ }^{1}$ Whether the structure of each country's distribution has any growth effect is an intriguing issue. This study defines the human capital dispersion of population as the degree of dispersion in population distribution in terms of educational attainment levels and empirically investigates the productivity growth implication of

\footnotetext{
${ }^{1}$ The average schooling years for Canada and Norway are 10.50 and 10.85 in 1990, respectively. However, in Canada, the shares of population aged 25 and over with primary, secondary, and tertiary level of education are $16 \%$, $34 \%$, and $43 \%$, respectively, whereas the corresponding figures are $11 \%, 70 \%$, and $18 \%$ for Norway.
} 
human capital dispersion based on a theoretical consideration regarding the form of human capital production technology. The findings will have a strong implication on education policy.

Theoretical consideration behind our inquiry stems from the generalization of the human capital production technology and the consideration of the measurement issue of human capital index. The common use of average index of schooling years to proxy human capital relies on the assumption that human capitals obtained from different levels of education are perfectly substitutable and that each additional educational year contributes to the productivity growth at a constant rate regardless of the education levels. Considering the fact that different types of knowledge are obtained at each level of education, a linear return function of education may be a crude approximation. If the return function exhibits convexity, implying that higher education contributes to productivity growth at a higher rate, a greater dispersion of a country's population distribution in terms of educational attainment levels would lead to a greater stock of aggregate human capital, given the same average schooling years in the population.

Recent empirical studies provide mixed assessments on the magnitude of social returns to human capital. When human capital is considered as a factor of input in a production function, empirical studies find that its impact on growth is insignificant as in Benhabib and Spiegel (1994), or even if it exists, that the returns beyond private returns are minimal or negative as in Pritchett (2001). ${ }^{2}$ On the other hand, when human capital is considered as a factor influencing productivity growth as suggested in endogenous growth models, its impact is found to be significant as shown in Benhabib and Spiegel (1994), Dinopoulos and Thompson (2000), and Bils and Klenow (2000). These findings suggest an existence of strong externality arising from human capital investments. This study contributes to the literature by considering the growth 
effect of human capital dispersion of population. Based on a pooled time-series data set of 94 developed and developing countries for the period of 1960 to 1995, the findings show that the human capital dispersion of population proxied by variance of educational attainment is strongly and positively correlated with productivity growth controlling for the average schooling years of population.

Only a handful of studies have looked into relationship between human capital dispersion and growth. Birdsall and Londoño (1997) find that the standard deviation of human capital has a negative relationship with per capita growth based on a cross-section data set of 43 countries. Lopez et al. (1998) develop a model where dispersion of human capital may influence the productivity level. They find that the standard deviation and coefficient of variability of schooling contribute negatively to per capita output in 12 developing economies. Our study differs from Lopez et al. (1998) in that we investigate the influence of human capital dispersion on output growth per labor rather than the level of output and extends the work of Birdsall and Londoño (1997) with an empirical study driven by a theoretical consideration of endogenous growth with human capital spillovers based on much richer set of data.

Thomas et al. (2000) and Castelló and Doménech (2002) find negative influence of human capital inequality on growth based on human capital Gini coefficient. Gini coefficient, a measure of human capital inequality, accounts for the degree of disproportionate distribution of education by quintiles of population and was intended to proxy the income inequality. However, as this study focuses on the degree of dispersion rather than the inequality in human capital, variance measure of educational attainment is utilized rather than Gini coefficient. ${ }^{3}$

\footnotetext{
${ }^{2}$ Refer to Krueger and Lindahl (2000) and Temple (2001) for more discussions on empirical issues in measuring social returns to human capital.

${ }^{3}$ Refer to Section 6 for the differences between the two measures and further discussions on measurement of human capital dispersion.
} 
The paper is organized as follows. Based on the discussion regarding the non-linearity in human capital production technology, Section 2 reasons why both average index and dispersion index of human capital should have growth implications. Section 3 provides data description. In Section 4, empirical model and econometric method used in the estimation are presented. Section 5 presents the empirical results and draws policy implications. Section 6 discusses measurement issues regarding human capital dispersion relating with the current literature. Section 7 provides concluding remarks.

\section{MODEL}

Investments in human capital are determined by individual optimization decisions based on the market incentives and government subsidies. Although endogenous growth models indicate that a society with higher incentives for human capital investments would generate higher growth, it is not clear how the social incentives for human capital should be structured across different education levels. This is an important issue since different structures will lead to different compositions of human capital in the population which may or may not have differential impact on the productivity growth. ${ }^{4}$ In this section, we consider the relevance of this issue based on the discussion about the form of human capital production technology.

Consider an economy where final output is produced by two factors of inputs, physical capital and labor. We assume a Cobb-Douglas production function with constant returns to scale (CRS) technology.

$$
Y_{i t}=A_{i t} K_{i t}{ }^{\beta} L_{i t}{ }^{1-\beta}, \quad(0<\beta<1)
$$

\footnotetext{
${ }^{4}$ Although it would be interesting to specifically model the decision process regarding human capital investments, we only focus on the productivity issue given that all the decisions regarding human capital investments have been already made.
} 
where $Y_{i t}, K_{i t}$, and $L_{i t}$ denote GDP, physical capital stock, and total labor in country $i$ at time $t$. Time-variant technological level $\left(A_{i t}\right)$ is influenced by the factors contributing to the enhancement of efficiency and knowledge environment.

Endogenous growth models of Lucas (1988), Romer (1990), and Jones (1995) provide theoretical frameworks where human capital enhances productivity growth. Other studies including works of Bartel and Lichtenberg (1987), Foster and Rosenzweig (1996), and Berman et al. (1998) have suggested that human capital enhances the adoption of technology or that human capital is complementary to technology use. Benhabib and Spiegel (1994), Bils and Klenow (2000), and Dinopoulos and Thompson (2000) introduce models where average human capital in the population influences the productivity growth. ${ }^{5}$ Following these empirical works, this study considers human capital per labor influencing the rate of technological progress. Catch-up effect is also incorporated in our model as in Nelson and Phelps (1966) to see whether a country grows faster when its technological level is more distant from the technological frontier. Consideration of both human capital and catch-up effect in relation to productivity growth are shown in the following equation.

$$
\dot{A}_{i t} / A_{i t}=c+\delta H_{i t} / L_{i t}+\gamma \log \left(A_{i t} / \bar{A}_{t}\right)
$$

where $\dot{A}_{i t}=d A_{i t} / d t$ and $c$ is a constant rate of technological progress. $H_{i t}$ represents the aggregate of the human capital present in the economy. $\overline{A_{t}}$ represents the technological level of the country with the frontier technology. $\delta$ and $\gamma$ represent, respectively, human capital effect and catch-up effect on the productivity growth.

\footnotetext{
${ }^{5}$ Jones (1995) and Dinopoulos and Thompson (2000) develop versions of Romer models without scale effects, as scale effects implied by endognenous growth models are not consistent with empirical evidence.
} 
Given that $h_{i j t}$ is the human capital of an individual $j$ in country $i$ at time $t$, aggregate human capital $\left(H_{i t}\right)$ is defined as the sum of the human capitals of individuals present in the economy.

$$
H_{i t}=\sum_{j=1}^{n_{i}} h_{i j t}
$$

where $n_{i}$ is the population of country $i$. The imposed assumption is that human capitals of individuals are perfectly substitutable when they are adjusted in terms of efficiency units. Human capital $\left(h_{i j t}\right)$ of each individual will be enhanced by acquisition of education $\left(s_{i j t}\right)$ and the skills obtained from work experience $\left(x_{i j t}\right)$.

$$
h_{i j t}=g\left(s_{i j t}, x_{i j t}\right)
$$

We concentrate on the functional form of $g$ with respect to $s_{i j t}$ at a given $x_{i j t}$ and consider that $g$ is solely a function of $s_{i j t}$ from here on. ${ }^{6}$ Most empirical studies relating human capital and growth assume that the function $g$ is linear, implying that each additional year of education increases human capital at a constant rate over all levels of education. This justifies the use of the average schooling year index as a measure of human capital per capita. Opportunity cost of investment in each additional schooling year is considered to be constant based on Mincerian empirical microeconomic specification relating wage premiums with individual educational characteristics as in Mincer (1974). Thus, the linearity in $g$ implies that the return to education in generating human capital is constant. However, given that different types of knowledge are acquired at each level of education, there may exist a non-linearity in the returns to education at different levels of education. Given the same amount of investments in education measured in terms of the opportunity cost or, in other words, given the same level of average schooling years 
in the population, the composition of aggregate human capital will matter if the return function is not linear. Depending on whether the function $g$ exhibits convexity or concavity, a greater or smaller dispersion of a country's human capital composition in terms of educational attainment levels will lead to a greater aggregate human capital and thus higher productivity growth.

To investigate whether a non-linearity exists in the human capital production technology, the function $g$ is approximated based on Taylor series expansion around the average schooling years $\left(\mu_{i t}\right)$ of the workers in country $i$ at time $t$.

$$
g\left(s_{i j t}\right) \cong g\left(\mu_{i t}\right)+g^{\prime}\left(\mu_{i t}\right)\left(s_{i j t}-\mu_{i t}\right)+g^{\prime \prime}\left(\mu_{i t}\right)\left(s_{i j t}-\mu_{i t}\right)^{2}
$$

Substituting equation (5) into equations (2) and (3), aggregate human capital per worker $\left(H_{i t} / L_{i t}\right)$ can be represented by average $\left(\mu_{i t}\right)$ and variance $\left(\sigma_{i t}^{2}\right)$ of schooling years of the workers as shown in equation (7). We denote the two variables as average index and dispersion index of human capital of country $i$ at time $t$, respectively.

$$
\begin{aligned}
& H_{i t} / L_{i t} \cong\left(1 / L_{i t}\right) \sum_{j=1}^{n_{i}}\left[g\left(\mu_{i t}\right)+g^{\prime}\left(\mu_{i t}\right)\left(s_{i j t}-\mu_{i t}\right)+g^{\prime \prime}\left(\mu_{i t}\right)\left(s_{i j t}-\mu_{i t}\right)^{2}\right] \\
& H_{i t} / L_{i t} \cong g\left(\mu_{i t}\right)+g^{\prime \prime}\left(\mu_{i t}\right) \sigma_{i t}^{2}
\end{aligned}
$$

Dividing each side of equation (1) by $L_{i t}$, we have the production function in intensity form. Incorporating equations (2) and (7) into the production function in intensity form and taking log differences, the following equation is derived.

$$
d \log y_{i t}=c+\beta \cdot d \log k_{i t}+\delta g\left(\mu_{i t}\right)+\delta g^{\prime \prime}\left(\mu_{i t}\right) \sigma_{i t}^{2}+\gamma \log \left(A_{i t} / \bar{A}_{t}\right)
$$

where $y_{i t}$ and $k_{i t}$ are output per worker $\left(Y_{i t} / L_{i t}\right)$ and physical capital per worker $\left(K_{i t} / L_{i t}\right)$, respectively.

\footnotetext{
${ }^{6}$ The influence of skills on human capital accumulation is not considered here due to the limitation on the availability of work experience data.
} 
The equation (8) implies that the growth rate of output per worker will depend on the variance of the schooling as well as the average schooling years of the workers. The functional form of $g$ suggests an important link between growth and human capital dispersion. Whether $g$ is convex or concave in $s_{i t}$ will determine the importance of human capital dispersion. If $g$ ” is not significantly different from zero, then the conventional use of average schooling years as the human capital index may be justified. However, if $g$ ” differs significantly from zero, then the dispersion of human capital has an additional growth implication. Positive $g$ ” will imply that there is an increasing return to schooling years in generating human capital and thus more dispersion in the population distribution in terms of educational attainment levels will generate higher growth, given the same average schooling. On the contrary, negative $g$ ” implies that homogeneity of the population in terms of its educational attainment levels leads to higher growth given the same average schooling.

Policy implication of this investigation on education policy is very strong. Given that a country has a constraint on the social resources devoted to education, our results will shed light on whether the government should support elitist educational system to generate a homogeneous population generating only a few elites or should support education at all levels to create more heterogeneity in the population in terms of human capital levels, when the objective of the government is to promote growth. It is true that the education policy of a country has to consider many other important dimensions regarding social welfare related to education policy such as income distribution effect or supplies and demands of skilled and unskilled labors in the labor market. However, this study only concentrates on the productivity aspect of education policy regarding the distribution of human capital in the population, with other issues being set aside. 


\section{DATA DESCRIPTION}

This study uses a pooled time-series data set of 94 countries from 1960 to 1995 compiled from two main sources: Penn World Tables (PWT Mark 6.1) of Heston et al. (2002) for traditional inputs and output data and Barro and Lee (2000) for educational attainment data. Since Barro and Lee (2000) provide education attainment data in five-year intervals, all other data are gathered accordingly in 5-year intervals. Real GDP, real investments, and number of workers are obtained from the PWT 6.1. Since capital stock series are not available in this new version of PWT, capital stocks are estimated from each corresponding real investment series for country $i$. First, the initial capital stocks $\left(K_{i 0}\right)$ are estimated based on the following formula.

$$
K_{i 0}=I_{i 0} /\left(d_{i}+q_{i}\right)
$$

where $I_{i 0}$ is the initial investment for country $i$. Retirement rates $\left(d_{i}\right)$ are assumed to be 5 percent and investment growth rates $\left(q_{i}\right)$ were calculated using the earliest ten years of investment data available for each country $i$. Given the estimates for initial capital stocks, the investments are then accumulated to form the subsequent stock series based on the perpetual inventory method.

The distribution of population with no schooling, primary education, secondary education, and tertiary education as well as the schooling years at each level were obtained from Barro and Lee (2000). Although post-graduate education, on-the-job-training (OJT) or firm-specific human capital investments all contribute to the improvement in the level of aggregate human capital of the population, they were excluded due to the difficulty of measurement and limited data availability. As discussed in the previous section, the aggregate human capital index $(H / L)$ depends on the specific form of $g$ which will be approximated by two measures in this study: average index $(\mu)$ and dispersion index $\left(\sigma^{2}\right)$ of human capital. Since the educational attainment levels data specific to labor force was not available, the indices were measured based on the 
educational attainment data of population aged 25 or older. ${ }^{7}$ The two indices for each country are calculated using the following formulae.

$$
\begin{aligned}
\mu_{i t} & =\sum_{a=0}^{3} m_{i t, a} \cdot p_{i t, a} \\
\sigma_{i t}^{2} & =\sum_{a=0}^{3}\left(m_{i t, a}-\mu_{i t}\right)^{2} \cdot p_{i t, a}
\end{aligned}
$$

where $a$ represents each level of education: no schooling $(a=0)$, primary $(a=1)$, secondary $(a=2)$, and tertiary education $(a=3) . p_{i t, a}$ is the share of the population aged 25 or older who have attained the education level $a$ and $m_{i t, a}$ is the average schooling years for those who have attained the educational level $a$ taking into consideration of the proportion of incompletes at each level. The measure takes into account of the differences in educational years at each level for each country. The formulae for $m_{i t, a}$ are as follows : $m_{i t, 0}=0, m_{i t, 1}=\left(\left(z_{i t, 1} / 2\right) p_{i t, 1}{ }^{n}+z_{i t, 1} p_{i t, 1}^{c}\right) / p_{i t, 1}, m_{i t, 2}=$ $\left(\left(z_{i t, 2} / 2+z_{i t, 1}\right) p_{i t, 2}{ }^{n}+\left(z_{i t, 2}+z_{i t, 1}\right) p_{i t, 2}{ }^{c}\right) / p_{i t, 2}$, and $m_{i t, 3}=\left(\left(z_{i t, 3} / 2+z_{i t, 2}+z_{i t, 1}\right) p_{i t, 3}{ }^{n}+\left(z_{i t, 3}+z_{i t, 2}+z_{i t, 1}\right) p_{i t, 3}^{c}\right) /$ $p_{i t, 3}$, where $z_{i t, a}$ is the schooling years for the educational level $a, p_{i t, a}{ }^{c}$ is the share of population who have attained and completed the level $a$, and ${p_{i t, a}}^{n}$ is the share of those who have attended but have not completed the level $a$ in country $i$. The average indices derived from the formula in (10) exactly match the average years of schooling data in Barro and Lee (2000).

Table 1 provides the distribution of population in terms of educational attainments, average index, and dispersion index of human capital for each group of economies for 1960 and 1995. The average schooling years are higher for the OECD economies than for the developing economies. The dispersion index for the OECD economies in 1995 are lower than those of Latin American economies and East Asian economies, but higher than those of Sub-Saharan economies. Both average and dispersion indices have increased from 1960 to 1995 for all groups

\footnotetext{
${ }^{7}$ The use of an alternative education data based on population aged 15 or older did not change our main findings.
} 
of economies. However, it is difficult to see any general distinguishing pattern of distribution or dispersion index across groups of economies.

Average indices are plotted against dispersion indices of human capital in Figure 1 which illustrates a wide range of dispersion at each level of average schooling years. As average schooling index increases, there is a tendancy that the range of dispersion index widens up to certain point, then narrows afterwards. The plots indicate that there is a particularly strong correlation between the two indices when both indices are at a very low level. This arises from the fact that the dispersion index increases naturally as literacy rate starts to rise from the zero schooling rate in the underdeveloped economies. In the empirical implementation, sensitivity analyses are performed using the sub-samples where these observation points are excluded.

As instrumental variables (IV) method is also considered in the following sections, additional exogenous variables are included as instruments. Arable land per person, life expectancy at birth, male population, female population, and fertility rate (births per woman) are taken from World Development Indicators, World Bank. Cotton prices, oil prices, iron prices, and wheat prices are obtained from International Financial Statistics, IMF. World population is obtained from U.N. Statistical Yearbook, U.N.

\section{ECONOMETRIC METHOD}

A linearized empirical model based on equation (8) is adopted to investigate whether average index and dispersion index of human capital have any significant growth implication. ${ }^{8}$

\footnotetext{
${ }^{8}$ The use of mean and variance measures in this study is analogous to the empirical approach in the finance literature where concavity assumption of utility function leads to the consideration of mean and variance of asset returns. An approach with the shares of population at each level of educational attainment included as regressors may be an alternative and more direct method to determine the existence of non-linearity. However, as the changes
} 
As the educational attainment data are available only for every 5 years, this study uses a pooled data set of 5-year interval growth rates.

$$
d \log y_{i t}=c+\beta \cdot d \log k_{i t}+\delta_{m} \mu_{i t}+\delta_{v} \sigma_{i t}^{2}+\gamma \log \left(A_{i t} / \bar{A}_{t}\right)+\varepsilon_{i t}
$$

The error term $\varepsilon_{i t}$ is assumed to be distributed i.i.d. $\left(0, \sigma_{\varepsilon}^{2}\right) .^{9} d \log y_{i t}$ and $d \log k_{i t}$ are $\left(\log y_{i t}-\log y_{i t-}\right.$ $\left.{ }_{5}\right) / 5$ and $\left(\log k_{i t}-\log k_{i t-5}\right) / 5$, respectively. Human capital indices are the averages of the initial and terminal year values for each 5-year interval. $c, \beta, \delta_{m}, \delta_{v}$, and $\gamma$ are parameters. If $\delta_{v}$ is statistically insignificant, the linearity in the education return function cannot be rejected. The sign of $\delta_{\nu}$ will give us an indication of whether the human capital dispersion raises or reduces the productivity growth. Catch-up variable $\left(A_{i t} / \bar{A}_{t}\right)$ is approximated by the average ratio of each country's per capita GDP relative to that of the US during the five years prior to the initial year of each interval. The lagged values are used in order to avoid biases due to possible correlation with the error term. ${ }^{10}$ We have taken the average of the past five-year values to smooth out shortrun fluctuations in per capita GDP. The expected sign of $\gamma$ is negative. To see if any differential effects are shown in a longer time-horizon, we have also performed regressions on a pooled data set of non-overlapping 10-year intervals where human capital indices are measured from the averages of the initial and terminal year observations for each 10 -year interval.

Ordinary least squares (OLS) method with White-heteroscedasticity adjustment is used in all estimations. We consider a fixed effect model along time dimension to allow for missing common time-specific shocks which may be significant with the panel data of 5-year or 10-year

\footnotetext{
in the shares of population at all levels are interrelated in a complicated way, this study moves away from this alternative approach and adopts the variance measure as a proxy for the degree of dispersion in the human capital distribution.

${ }^{9}$ More specifically, the error term is the average of annual error terms within the five-year interval.

${ }^{10}$ Contemporaneous values may be correlated with the error term. By using lagged values, the estimates will be consistent if there are no serial correlations in the error terms. Since the estimation results do not show signs of serial
} 
intervals. As our data set is an unbalanced panel with some countries having mere one or two observation points, country-specific fixed effects estimation may significantly reduce the degrees of freedom. Our base model does not consider country-specific constants, which allows us to capture between-country as well as within-country variations. Instead, regional dummies for Latin American countries and for Sub-Saharan countries were included in alternative specifications. Additionally, random-effects estimations were performed on the base model.

To determine whether the main results depend on the CRS assumption, an alternative empirical model is estimated based on the original production function specification, however, without constant returns to scale assumption. $\beta_{k}$ and $\beta_{l}$ are, respectively, output elasticity with respect to physical capital and to labor.

$$
d \log Y_{i t}=c+\beta_{k} \cdot d \log K_{i t}+\beta_{l} \cdot d \log L_{i t}+\delta_{m} \mu_{i t}+\delta_{v} \sigma_{i t}^{2}+\gamma \log \left(A_{i t} / \bar{A}_{t}\right)+\varepsilon_{i t}
$$

As output, capital, labor, and indices of human capital may have been determined endogenously in a system of structural equations which is not fully specified in this study, our regression is potentially subject to an endogeneity problem which may lead to biases in the estimates. Therefore, instrumental variables (IV) method is considered for both equations (12) and (13). In addition to time-specific constants, regional dummies, and catch-up variable, the 5year lagged values of capital stock growth, labor growth, average index and dispersion index of human capital are used as instruments under the assumption that economic agents are unable to anticipate future economic shocks to the environment. Nine additional instruments are included and they are as follows. Arable land per person, world price of cotton, oil, and iron relative to wheat may be correlated with the decision on capital investments as they will influence the cost of production. The life expectancy at birth, male population, female population, fertility rate 
(births per woman), and world population may be considered as exogenous factors reflecting the environment which influences the labor and human capital formation (average index and dispersion index). The exogeneity tests based on Hausman specification tests were performed on the latter nine additional variables, where we could not reject the null hypothesis of exogeneity for all nine. ${ }^{11}$

As labor in the original specification is the total number of workers in an economy, it does not appropriately represent labor in terms of its efficiency units. In an alternative specification, the study adopts a method similar to the one used by Bils and Klenow (2000) in adjusting labor in order to incorporate educational quality. ${ }^{12}$ Following is a Mincerian equation relating wage premiums with schooling years of individuals, but without consideration for years of experience.

$$
\log w\left(s_{i j t}\right)=\log w_{0}+r_{h} s_{i j t}
$$

where $w\left(s_{i j t}\right)$ is the wage for an individual $j$ with $s_{i j t}$ years of schooling, $w_{0}$ is the wage for the unskilled, and $r_{h}$ is a positive constant. Assuming a competitive labor market, wage represents private returns to educational investment as well as the efficiency level of an individual. Using equation (14), equation (15) shows individual labor adjusted for efficiency increase due to education acquisition.

$$
l_{i j t}^{*}=a_{0} \exp \left(r_{h} \cdot s_{i j t}\right) l_{i j t}
$$

\footnotetext{
year lagged variables as alternative approximations of catch-up variable did not alter the main findings of this study. ${ }^{11}$ The null hypothesis of exogeneity could not be rejected for the nine variables in both 5 -year and 10-year interval regressions of model (12) with time-specific constants, as chi-squared statistics show chisq(9) $=0.090$ with a pvalue of 0.999 and $\operatorname{chisq}(9)=1.659$ with a p-value of 0.996 , respectively.

${ }^{12}$ The literature treating human capital as an independent factor of input considers Mincerian wage equation to calculate the private returns and then to estimate social returns to human capital such as in Pritchett (2001). As Mincerian equation implies non-linearity in the calculation of human capital as inputs, a simple average index of human capital will allow us a biased estimate of human capital.
} 
where $l_{i j t}^{*}$ is labor in efficiency units and $a_{0}$ is a constant. Total labor in efficiency units $\left(L^{*}{ }_{i t}\right)$ is calculated based on the distribution data on educational attainment level as follows. ${ }^{13}$

$$
L_{i t}^{*}=\sum_{a=0}^{3} \exp \left(r_{h} \cdot m_{i t, a}\right) p_{i t, a} L_{i t}
$$

$r_{h}$ is assumed to be 0.10 which is obtained from the empirical studies based on micro-level data. ${ }^{14}$ Substituting $L_{i t}$ in equation (1) with $L^{*}{ }_{i t}$ and deriving the empirical equation similar to equation (12), we have the following empirical model.

$$
d \log y_{i t}^{*}=c+\beta \cdot d \log k_{i t}^{*}+\delta_{m} \mu_{i t}+\delta_{v} \sigma_{i t}^{2}+\gamma \log \left(A_{i t} / \bar{A}_{t}\right)+\varepsilon_{i t}
$$

where $y_{i t}^{*}\left(=Y_{i t} L^{*}{ }_{i t}\right)$ and $k_{i t}^{*}\left(=K_{i t} / L^{*}{ }_{i t}\right)$ are, respectively, output and physical capital per efficiency unit of worker.

\section{EMPIRICAL RESULTS AND IMPLICATIONS}

Table 2 provides estimations of production function in intensity form with growth rates of inputs and outputs. The estimations are based on equation (12) with average growth rate of GDP per worker as the dependent variable. Models (i) - (v) are 5-year interval regressions and models (vi) - (x) are 10-year interval regressions. The estimated output elasticities with respect to physical capital in all models $(0.407-0.430)$ are fairly close to the actual capital shares of GDP (ranging from 0.3 to 0.4 ). In all models of Table 2, both average index and dispersion index of human capital are shown to be statistically significant with positive signs. ${ }^{15}$ Their effects are

\footnotetext{
${ }^{13}$ Similar specifications of labor quality adjustment can be found in Hall and Jones (1999) and in Temple (2001).

${ }^{14}$ Psacharopoulos (1993) shows that wage increments range from 8.2 to 13.2 percent per additional year of schooling depending on regions with an overall average of 10.1 percent.

${ }^{15}$ Average index and dispersion index of human capital are also statistically significant when they are included each separately in the regressions.
} 
robust even when catch-up variables are included as shown in models (iii), (v), (viii), and (x). ${ }^{16}$ Inclusion of regional dummies had little effect on the qualitative results regarding indices of human capital as shown in models (iv), (v), (ix), and (x).

The dispersion index of human capital has a stable positive sign and its coefficient is robustly significant. This result shows evidence of convexity in the human capital production technology. Our results which strongly suggest positive productivity growth effect of dispersion index are in stark contrast with earlier findings of Lopez et al. (1998), Birdsall and Londoño (1997) and Castelló and Doménech (2002). The results of Lopez et al. (1998) may have been influenced by the selection of countries, as only a small sample of developing economies were included where the standard deviation and mean are generally strongly correlated due to the fact that the standard deviation is close to zero when a large share of the population has no education. The estimation results of Birdsall and Londoño (1997) are obtained based on a limited number of cross-section observations (43 observations) with inclusion of many other explanatory variables, resulting in small degrees of freedom. Our study may provide better and conclusive evidence as it is based on a richer set of data. The contrast with the results of Castelló and Doménech (2002) may be explained by the fact that the human capital Gini coefficient is found to have a negative correlation with our dispersion measure as discussed in Section 6.

The average index of human capital is consistently significant as in Benhabib and Spiegel (1994). However, in contrast to their findings, the average index of human capital is substantially significant even without inclusion of the catch-up variable or without interaction with the catchup variable. ${ }^{17}$ Comparison of models (i) and (iii) indicates that the coefficient estimates of

\footnotetext{
${ }^{16}$ The estimate results in Table 2 do not show signs of serial correlations in the error terms. Durbin-Watson statistics for our estimates on the pooled data set are 1.998, 1.967, and 2.022 for the models (i), (iii), and (v), respectively.

${ }^{17}$ Benhabib and Spiegel (1994) find that average index becomes significant only when catch-up variable is included or when it is interacted with the catch-up variables. The average index of human capital in our model enters in levels,
} 
average human capital index rise significantly when the catch-up variable is included. ${ }^{18}$ The reason may lie in the fact that the two variables are significantly correlated. Regardless of these issues, however, the coefficient estimates for dispersion index remain very stable in all specifications. The coefficient estimates for catch-up variable show the correct sign of negativity, supporting the convergence hypothesis.

Hausman specification tests of random effects against fixed effects model are performed for models (i) and (v) where the tests cannot conclusively reject random effects model for both models. ${ }^{19}$ Random effects estimates are shown in columns (ii) and (vii) and we observe that the consideration of random effects does not alter the qualitative findings on human capital indices.

As mentioned in Section 3, the average index and the dispersion index are strongly correlated for underdeveloped countries with no schooling rate close to one. Although we have already considered regional dummies and catch-up variables which may control for the potential biases due to this issue, we check further whether our results are robust to exclusion of these observation points. Models (i) and (ii) in Table 3 use a sub-sample of observations with the average index higher than 1, while models (iii) and (iv) in Table 3 use a sub-sample with the dispersion index greater than 4 . These sub-samples effectively eliminate observations for the underdeveloped countries with no schooling rate close to one for which the correlations between the two indices are relatively strong. The average index and dispersion index remain strongly significant in all sub-sample regressions.

not in log level form as in Benhabib and Spiegel (1994). In addition, human capital data used in our study is from Barro and Lee (2000), whereas Benhabib and Spiegel obtain human capital data from Kyriacou (1991).

${ }^{18}$ The same effects can also be seen between (iv) and (v), between (vi) and (viii), between (ix) and (x), and also in Benhabib and Spiegel (1994).

${ }^{19}$ Hausman specification tests of country-specific random effects against fixed effects show chisquared statistics of chisq(8) $=17.872$ with $p$-value of 0.013 and chisq(5) $=14.144$ with $p$-value of 0.015 for 5 -year and 10 -year interval regressions, respectively. 
In models (v) and (vi) of Table 3, labor was augmented with educational quality adjustment based on equation (16). Regressions based on equation (17) with productivity growth per efficiency unit of labor as the dependent variable show that the estimates for dispersion index remain robustly significant. All parameter estimates under these models show very little difference when compared with the results with raw labor in Table 2.

Models (vii) and (viii) are IV estimates for the full sample for 5-year and 10-year regressions. ${ }^{20}$ Comparing these two models with the OLS estimates of models (iii) and (viii) in Table 2, we find that the IV method estimations produce relatively lower coefficient estimates, but do not alter the qualitative findings of OLS estimation. The estimated technological share of physical capital now lies within the range of its actual share.

In Table 4, the aggregate production function is estimated in its original form with growth rates, but without imposition of the constant returns to scale assumption as in equation (13). The dependent variable is the growth rate of GDP. In models (i) and (iv) of Table 4, OLS estimates indicate that both average index and dispersion index of human capital positively influence the productivity growth in this alternative specification. The labor elasticity is substantially lower than the actual labor shares. The reason might be due to the endogeneity problem that we have discussed in the previous section. IV method estimations are performed on the equation (13) and the estimates are provided in models (ii), (iii), (v), and (vi) where labor elasticities gain significance with larger estimates. The output elasticities with respect to both physical capital and labor are relatively closer to their actual shares. The main findings on the human capital indices are robust to IV estimations.

\footnotetext{
${ }^{20}$ The sample for IV estimation is limited by the availability of instruments.
} 
To evaluate the quantitative significance of the dispersion index against the actual data, we compare, as an example, two countries with similar levels of average schooling years but with substantially different distributions of population in terms of educational attainment. In 1990, Canada and Norway had comparable average indices of human capital (10.50 and 10.85, respectively). However, the dispersion indices differed vastly for the two countries (20.15 for Canada and 8.60 for Norway). Given our estimates of model (iii) in Table 2, we conclude that growth rate of output per worker in Norway would have been higher by 1.03 percentage points than the actual rate if Norway had its human capital distribution similar to that of Canada. ${ }^{21}$ As the actual average annual growth rate of output per worker in Norway was 2.05 percent for 1985 1995 (2.97 percent for 1990-2000), the magnitude of the hypothetical increase is substantial.

\section{MEASUREMENT ISSUES OF DISPERSION OF HUMAN CAPITAL}

Many earlier studies in the human capital literature have adopted variance and standard deviation as measures of human capital dispersion. Variance is discussed in Ram (1984), Winegarden (1979), Fields (1980), and Marin and Psacharopoulos (1976), while standard deviation is used in Ram (1990) and Birdsall and Londoño (1997). Our study has chosen variance over standard deviation as the measure of the dispersion index of human capital, as it is consistent with the variables in our model which was derived based on a Taylor series approximation of a non-linear education return function. The use of standard deviation as dispersion index did not change the qualitative findings of the study. ${ }^{22}$

\footnotetext{
${ }^{21}$ Another example would be a comparison between Bolivia and Jamaica which had comparable levels of average indices (4.74 and 4.55, respectively), but very different dispersion indices (24.63 and 10.48, respectively).

${ }^{22}$ The results are available upon request.
} 
One concern regarding the use of standard deviation (or variance likewise) as a dispersion index was raised by Ram (1990) who found that the standard deviation has a strong curvilinear relationship with the mean. The relationship may be partly caused by a technical aspect that the standard deviation will be zero by definition either when the mean is zero or at its maximum value.

Table 5 presents OLS estimates from the regressions of standard deviation (or variance) on mean and mean squared of schooling years based on the data set from Ram (1990) and based on the data set of this study. Constants are naturally suppressed in all except (ii) to be consistent with the relationship between the two measures: mean and standard deviation (or variance). Models (i) - (iii) based on the data set of Ram (1990) and models (iv) - (vii) based on our data set all reveal the curvilinear relationship. ${ }^{23}$ However, it is notable that even though the curvilinear relationship is confirmed in all regressions, the hypothesized correlation is far from perfect. The adjusted $\mathrm{R}^{2}$ for the regressions with variance as the dependent variable are 0.365 and 0.491 as shown in models (iii) and (v). ${ }^{24}$ When we eliminate the observations with low means or low standard deviations from our data set as in (vi) and (vii), the adjusted $\mathrm{R}^{2}$ becomes even lower (0.327 and 0.314 for (vi) and (vii), respectively).

The suggested relationship looks strong in Figure 1 of Ram (1990), which may be due to the fact that the study uses cross-section data where there is a little variation of standard deviation for each level of mean. However, as can be seen in Figure 1 of this study which is based on our pooled time-series data set, we can observe huge variation of standard deviation (or

\footnotetext{
${ }^{23}$ This purely empirical relationship is also confirmed in Thomas et al. (2000).

${ }^{24}$ The regression with standard deviation as the dependent variable based on Ram's data set shown in model (i) resulted in the adjusted $\mathrm{R}^{2}$ of 0.366 in our study, whereas Ram (1990) reports it to be 0.95 . The coefficient estimates are exactly matched in both, but the discrepancy exists in the reported adjusted $\mathrm{R}^{2}$. However, our regression with the inclusion of a constant shown in model (ii) matched Ram's findings in terms of coefficient estimates and adjusted $\mathrm{R}^{2}$
} 
variance) for each level of mean. These evidences suggest that the use of mean and mean squared measure of schooling years will not be sufficient to capture the total variations in standard deviation or variance and, in turn, to proxy the aggregate human capital present in the economy. ${ }^{25}$ Furthermore, the curvilinear relationship lacks theoretical support.

Coefficient of variation was considered as an alternative measure of relative dispersion in Lopez et al. (1998). The measure will appropriately adjust the dispersion measure in relative terms when the standard deviation has a tendency to increase with the mean. As discussed above, the relationship between the two latter measures is not in a simple linear form. More importantly, a critical problem of this index for our study is that this measure is indeterminate and unintuitive when the mean is close to zero. It may take a value far from zero when the mean is close to zero, which is counterintuitive and may result in mismeasurement of dispersion.

Thomas et al. (2000) and Castelló and Doménech (2002) estimate the inequality in education using Gini coefficient for human capital which accounts for the degree of disproportionate distribution of education by quintiles of population. While human capital Gini coefficient may appropriately represent inequality in schooling and in turn inequality in income, it may not be adequate in measuring the dispersion of human capital for our study. A clear and simple example can be seen in the following. According to Castelló and Doménech (2002), Yemen in 1975 had a human capital Gini index of 0.990 as $98.8 \%$ of the population had no schooling and all education was concentrated in the rest of the population. However, a country will have a zero human capital Gini index if all the population has the same degree of positive educational attainment. In terms of variance measure, both cases will have zero or close to zero

(0.40) as presented in footnote 10 of Ram (1990). Our report on adjusted $\mathrm{R}^{2}$ for model (i) is very much in line with that of the model (ii) in both studies. 
variance which is consistent with the intuition considering the homogeneity of human capital in terms of educational attainment. ${ }^{26}$ The variance will effectively reflect the degree of dispersion. The example shows that the human capital Gini index as a dispersion measure may be especially problematic for the developing economies where only a relatively small share of population has education.

\section{CONCLUDING REMARKS}

The study examines the significance of human capital dispersion on the productivity growth based on production function regressions against a 5-year interval pooled time-series data set of 94 developed and developing economies.

Controlling for catch-up effect, regional and time dummies, the empirical results provide strong evidence that both average index and dispersion index of human capital contribute positively to the productivity growth. The findings on the average index of human capital support earlier theoretical literature on human capital effect on productivity growth. Most interesting result in this study is that more dispersion of population distribution in terms of educational levels adds to the productivity growth, contrary to the previous findings. This evidence is consistent with the theoretical discussion regarding the existence of non-linearity in human capital production technology in Section 2 . The results of this study support the convexity hypothesis where each additional education year at a higher level raises the human capital of individual at an increasing rate.

\footnotetext{
${ }^{25}$ In addition to the discussed relationship, we found the skewness measure to be negatively correlated with the variance measure. However, the skewness measure was not statistically significant when included in the growth regression along with the average and dispersion indices.

${ }^{26}$ The two measures are very different and have a negative correlation where the correlation coefficient was -0.345 , based on the human capital Gini index data set obtained from Castelló and Doménech (2002) and the dispersion index data of this study. This may explain why the two studies give opposite results.
} 
The findings in this study imply that given the limited social resources for education, an economy would perform better when it allocates resources to support all levels of education, rather than when it focuses on promoting one particular level of education, for example, basic education. The implication may be especially strong for the underdeveloped economies when they optimize their education policy strategy targeting growth. A more detailed data set on the distribution of educational attainment would help us derive a more accurate measure of dispersion to differentiate the degrees of dispersion amongst the advanced economies. Furthermore, it would be interesting to investigate the degree of complementarity amongst different types of labors distinguished by their educational attainments and by area of study. These issues remain for future research. 


\section{REFERENCES}

Barro, R. J., 1991, Economic growth in a cross section of countries, Quarterly Journal of Economics 106(2), May, 407-443.

Barro, R. J. and J.-W. Lee, 2000, International data on educational attainment: Updates and implications, Center for International Development at Harvard University, Working Paper no. 42 ( http://www.cid.harvard.edu/ciddata/ciddata.html ).

Bartel, A. and F. Lichtenberg, 1987, The comparative advantage of educated workers in implementing new technology, Review of Economics and Statistics 69(1), Feb., 1-11.

Benhabib, J. and M. Spiegel, 1994, The role of human capital in economic development: Evidence from aggregate cross-country data, Journal of Monetary Economics 34, 143-173.

Berman, E., J. Bound, and S. Machin, 1998, Implications of skill-biased technical change: international evidence, Quarterly Journal of Economics 113(4), Nov., 1245-1279.

Bils, M. and P. Klenow, 2000, Does schooling cause growth? American Economic Review 90(5), 1160-1183.

Birdsall, N. and J. L. Londoño, 1997, Asset inequality matters: an assessment of the World Bank's approach to poverty reduction, American Economic Review 87(2), 32-37.

Castelló, A. and R. Doménech, 2002, Human capital inequality and economic growth: Some new evidence, The Economic Journal 112, March, C187-C200.

Dinopoulos, E and P. Thompson, 2000, Enodgenous growth in a cross-section of countries, Journal of International Economics 51(2), 335-362.

Fields, G. S., 1980, Education and income distribution in developing countries: A review of the literature, in Timothy Kong (ed.), Education and Income, World Bank Staff Working Paper No. 402, July 1980, 231-315. 
Foster, A. D. and M. R. Rosenzweig, 1996, Technical change and human-capital returns and investments: Evidence from the green revolution, American Economic Review 86(4), Sept., 931-953.

Hall, R. and C. I. Jones, 1999, Why do some countries produce so much more output per worker than others? Quarterly Journal of Economics 114, 83-116.

Heston, A., R. Summers, and B. Aten, 2002, Penn World Table Version 6.1, Center for International Comparisons at the University of Pennsylvania (CICUP).

Jones, C. I., 1995, R\&D-based models of economic growth, Journal of Political Economy 103, 759-784.

Krueger, A. B. and M. Lindahl, 2000. Education for growth: Why and for whom? NBER Working Papers No. 7591, March.

Kyriacou, G., 1991, Level and growth effects of human capital: A cross-country study of the convergence hypothesis, New York University Economic Research Report 91-26.

Lopez, R., V. Thomas, and Y. Wang, 1998, Addressing the education puzzle: The distribution of education and economic reforms, World Bank Working Papers 2031.

Lucas, R., 1988, On the mechanics of economic development, Journal of Monetary Economics 22(1), July, 3-42.

Marin, A., and G. Psacharopoulos, 1976, Schooling and income distribution, The Review of Economics and Statistics 58, 383-392.

Mincer, J., 1974, Schooling, experience, and earnings, Columbia University Press, New York.

Nelson, R. and E. Phelps, 1966, Investment in humans, technological diffusion, and economic growth, American Economic Review 56(2), May, 69-75. 
Pritchett, L., 2001, Where has all the education gone? World Bank Economic Review 15(3), $367-391$.

Psacharopoulos, G., 1993, Returns to investment in education: a global update, Policy Research Paper 1067, World Bank, Washington D.C.

Ram, R., 1984, Population increase, economic growth, educational inequality, and income distribution: Some recent evidence, Journal of Development Economics 14, 419-428.

Ram, R., 1990, Educational expansion and schooling inequality: International evidence and some implications, The Review of Economics and Statistics 72(2), 266-274.

Romer, P. M., 1990, Endogenous technological change, Journal of Political Economy 98, S71S102.

Temple, J., 2001, Generalizations that aren't? Evidence on education and growth, European Economic Review 45, 905-918.

Thomas, V., Y. Wang, and X. Fan, 2000, Measuring education inequality: Gini coefficients of education, mimeo, World Bank. (http://econ.worldbank.org/files/1341_wps2525.pdf)

Winegarden, C. R., 1979, Schooling and income distribution: Evidence from international data, Economica 46, 83-87. 
[Table and Figure Appendix]

Table 1. Distribution of population in terms of educational attainment levels.

\begin{tabular}{|c|c|c|c|c|c|c|}
\hline & $\begin{array}{c}\text { All } \\
\text { economies }\end{array}$ & $\begin{array}{c}\text { OECD } \\
\text { economies }\end{array}$ & $\begin{array}{c}\text { Developing } \\
\text { economies }\end{array}$ & $\begin{array}{c}\text { East and } \\
\text { South Asia }\end{array}$ & $\begin{array}{c}\text { Latin } \\
\text { America }\end{array}$ & $\begin{array}{c}\text { Sub-Saharan } \\
\text { Africa } \\
\end{array}$ \\
\hline \multicolumn{7}{|l|}{ Year of 1960} \\
\hline \multicolumn{7}{|l|}{ Percentage of population with: ${ }^{c}$} \\
\hline No schooling & 0.344 & 0.121 & 0.474 & 0.411 & 0.301 & 0.674 \\
\hline Primary education & 0.473 & 0.581 & 0.410 & 0.428 & 0.571 & 0.273 \\
\hline Secondary education & 0.150 & 0.237 & 0.099 & 0.126 & 0.109 & 0.050 \\
\hline Tertiary education & 0.031 & 0.055 & 0.016 & 0.036 & 0.020 & 0.003 \\
\hline Average index of human capital ${ }^{d}$ & 4.04 & 6.02 & 2.88 & 3.79 & 3.59 & 1.59 \\
\hline Minimum & 0.56 & 2.33 & 0.56 & 2.28 & 2.39 & 0.56 \\
\hline Maximum & 8.94 & 8.94 & 8.21 & 6.87 & 4.99 & 3.79 \\
\hline Dispersion index of human capital ${ }^{\mathrm{e}}$ & 10.01 & 10.78 & 9.57 & 14.31 & 10.66 & 6.07 \\
\hline Minimum & 2.07 & 4.38 & 2.07 & 9.96 & 3.50 & 2.07 \\
\hline Maximum & 22.84 & 20.78 & 22.84 & 17.55 & 22.84 & 17.13 \\
\hline \multicolumn{7}{|l|}{ Year of 1995} \\
\hline \multicolumn{7}{|l|}{ Percentage of population with: ${ }^{\mathrm{c}}$} \\
\hline No schooling & 0.253 & 0.048 & 0.348 & 0.164 & 0.136 & 0.501 \\
\hline Primary education & 0.376 & 0.364 & 0.381 & 0.360 & 0.502 & 0.335 \\
\hline Secondary education & 0.263 & 0.403 & 0.199 & 0.351 & 0.247 & 0.145 \\
\hline Tertiary education & 0.107 & 0.185 & 0.071 & 0.125 & 0.113 & 0.018 \\
\hline Average index of human capital ${ }^{d}$ & 5.92 & 8.76 & 4.60 & 7.27 & 6.16 & 2.95 \\
\hline Minimum & 0.67 & 5.24 & 0.67 & 4.03 & 4.48 & 0.67 \\
\hline Maximum & 12.18 & 12.18 & 8.54 & 10.09 & 7.60 & 7.78 \\
\hline Dispersion index of human capital $^{\mathrm{e}}$ & 17.18 & 15.96 & 17.75 & 19.45 & 20.38 & 11.49 \\
\hline Minimum & 3.95 & 8.90 & 3.95 & 15.46 & 12.07 & 3.95 \\
\hline Maximum & 35.45 & 20.55 & 35.45 & 22.54 & 29.64 & 23.20 \\
\hline
\end{tabular}

\footnotetext{
${ }^{a}$ Source: Barro and Lee (2000)
}

${ }^{\mathrm{b}}$ All countries considered in 5-year interval regressions are included in the calculation.

${ }^{\mathrm{c}}$ Includes persons aged 25 or older who have attended but may or may not have completed respective level of education.

${ }^{d}$ Statistics regarding the percentage of population with incomplete education at each level were additionally considered in the calculation. The calculation for average index is described in equation (10) of Section 3.

${ }^{\mathrm{e}}$ Dispersion index is the variance of schooling years in the population which is described in equation (11) of Section 3. 
Figure 1. Average index and dispersion index of human capital. ${ }^{a}$

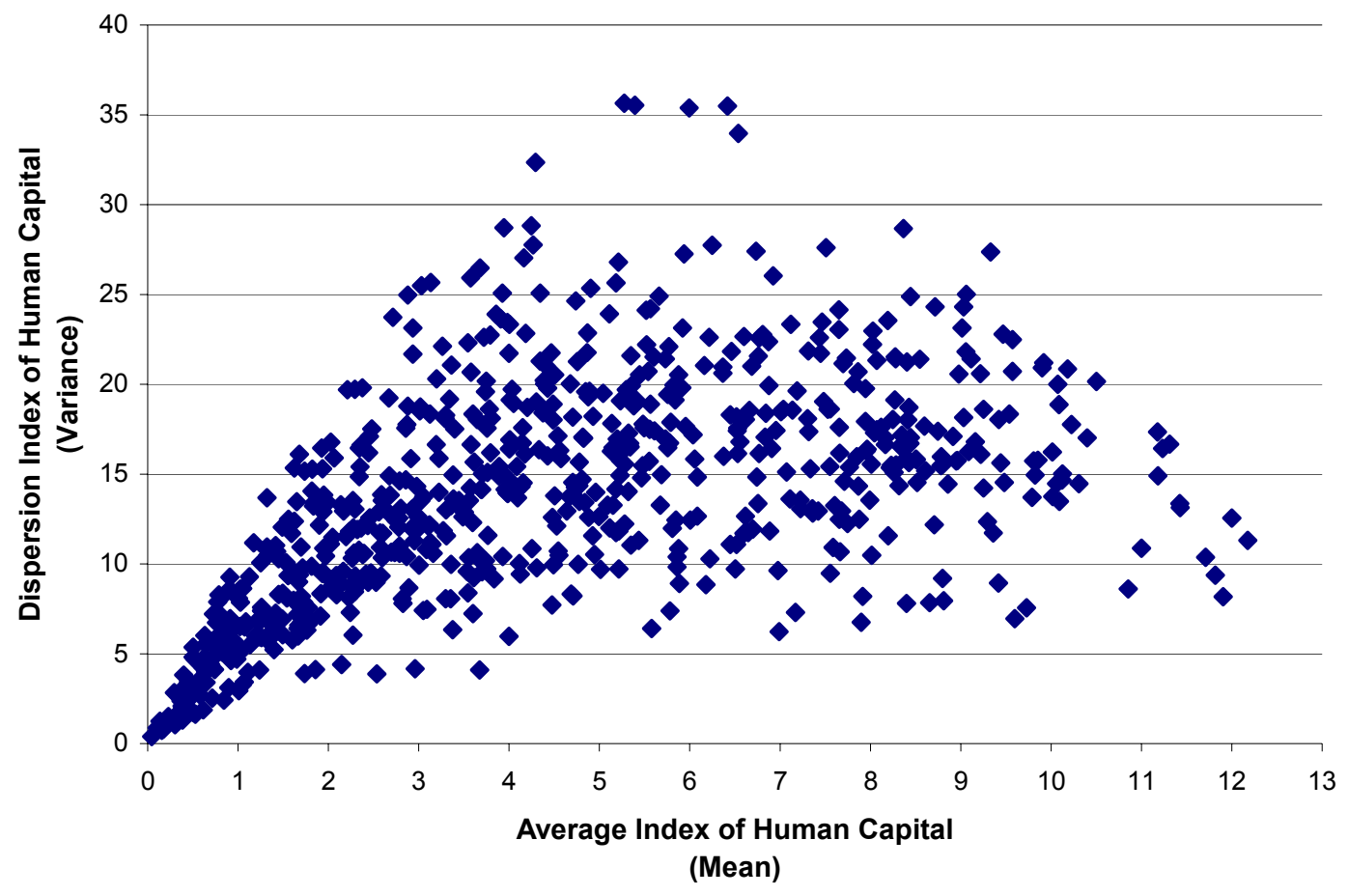

${ }^{a}$ Source: Barro and Lee (2000). All observations considered in 5-year interval regressions are included in the scatter plot. Average index is the average schooling years of population and dispersion index is the variance of the schooling years in the population. Calculations of both indices are described in equations (10) and (11) of Section 3. 
Table 2. Production function estimation in intensity form. (Dependent variable : $d \log y^{\mathrm{a}}$ )

\begin{tabular}{|c|c|c|c|c|c|c|c|c|c|c|}
\hline \multirow[b]{2}{*}{ Variables } & \multicolumn{5}{|c|}{$\begin{array}{c}\text { 5-year interval } \\
\text { regressions }\end{array}$} & \multicolumn{5}{|c|}{$\begin{array}{c}\text { 10-year interval } \\
\text { regressions }\end{array}$} \\
\hline & (i) & (ii) $^{\mathbf{c}}$ & (iii) & (iv) & (v) & (vi) & $\left(\right.$ viii $^{\mathrm{c}}$ & (viii) & (ix) & $(\mathbf{x})$ \\
\hline \multirow[t]{2}{*}{ dlogk } & $0.423^{* * *}$ & $0.425^{* * *}$ & $0.429^{* * *}$ & $0.411^{* * *}$ & $0.414^{* * *}$ & $0.430^{* * *}$ & $0.430^{* * *}$ & $0.423^{* * *}$ & $0.418^{* * *}$ & $0.407^{* * *}$ \\
\hline & $(0.038)$ & $(0.032)$ & $(0.039)$ & $(0.040)$ & $(0.042)$ & $(0.043)$ & $(0.035)$ & $(0.045)$ & $(0.046)$ & $(0.050)$ \\
\hline \multirow[t]{2}{*}{$\mu$} & $0.126^{* * *}$ & $0.138^{* * *}$ & $0.267^{* * *}$ & $0.089^{*}$ & $0.257^{* * *}$ & $0.118^{* *}$ & $0.133^{* *}$ & $0.260^{* * *}$ & $0.081^{*}$ & $0.252^{* * *}$ \\
\hline & $(0.042)$ & $(0.055)$ & $(0.084)$ & $(0.048)$ & $(0.084)$ & $(0.046)$ & $(0.058)$ & $(0.087)$ & $(0.049)$ & $(0.086)$ \\
\hline \multirow[t]{2}{*}{$\sigma^{2}$} & $0.086^{* * *}$ & $0.074^{* * *}$ & $0.089^{* * *}$ & $0.075^{* * *}$ & $0.072^{* * *}$ & $0.093^{* * *}$ & $0.079^{* * *}$ & $0.094^{* * *}$ & $0.079^{* * *}$ & $0.077^{* * *}$ \\
\hline & $(0.025)$ & $(0.027)$ & $(0.025)$ & $(0.026)$ & $(0.026)$ & $(0.029)$ & $(0.029)$ & $(0.028)$ & $(0.030)$ & $(0.030)$ \\
\hline \multirow[t]{2}{*}{$\log \left(A_{0} / \overline{A_{0}}\right)$} & & & $-0.497^{* *}$ & & $-0.643^{* * *}$ & & & $-0.480^{*}$ & & $-0.612^{* *}$ \\
\hline & & & $(0.244)$ & & $(0.245)$ & & & $(0.260)$ & & $(0.256)$ \\
\hline \multicolumn{11}{|c|}{ Regional constants $^{d}$} \\
\hline \multirow[t]{2}{*}{ Latin America } & & & & -0.259 & -0.216 & & & & -0.181 & -0.188 \\
\hline & & & & $(0.338)$ & $(0.327)$ & & & & $(0.325)$ & $(0.320)$ \\
\hline \multirow[t]{2}{*}{ Sub-Saharan } & & & & -0.581 & $-0.838 * *$ & & & & -0.599 & -0.764 \\
\hline & & & & $(0.404)$ & $(0.419)$ & & & & $(0.439)$ & $(0.454)^{*}$ \\
\hline $\mathbf{R}^{2}$ & 0.357 & 0.356 & 0.366 & 0.360 & 0.373 & 0.475 & 0.474 & 0.488 & 0.480 & 0.495 \\
\hline Adjusted $R^{2}$ & 0.347 & 0.347 & 0.356 & 0.348 & 0.360 & 0.465 & 0.464 & 0.476 & 0.466 & 0.480 \\
\hline $\begin{array}{l}\text { Number of } \\
\text { Observations }\end{array}$ & 544 & 544 & 540 & 544 & 540 & 270 & 270 & 268 & 270 & 268 \\
\hline $\begin{array}{l}\text { Number of } \\
\text { Countries }\end{array}$ & 94 & 94 & 94 & 94 & 94 & 94 & 94 & 94 & 94 & 94 \\
\hline
\end{tabular}

${ }^{a} d \log X$ is $100 *\left(\log X_{t}-\log X_{t-T}\right) / T(T=5$ or 10$)$ which is average annual growth rates of $X$ for T-year intervals in percentages. $y, k, \mu$, and $\sigma^{2}$ are GDP per worker, physical capital per worker, average index of human capital, and dispersion index of human capital, respectively. Human capital indices are the averages of the initial and terminal year values for each T-year interval. $A_{0} / \bar{A}_{0}$ is the average ratio of GDP per capita relative to that of the U.S. during the five years prior to the initial year of respective intervals. All estimates are ordinary least squares estimates and the numbers in the parentheses are White-heteroscedastic consistent standard errors. All models include unreported time-specific constants.

${ }^{\mathrm{b}} 5$-year interval regressions are based on a pooled data set using the following 5-year interval data: 1965-70, 1970$75,1975-80,1980-85,1985-90$, and 1990-95. 10-year interval regressions are based on a pooled data set using the following 10-year interval data: 1965-75, 1975-85, and 1985-95.

${ }^{\mathrm{c}}$ Random effects models are considered.

${ }^{\mathrm{d}}$ Regional constants are one for countries within each region and zero for the rest.

${ }^{*},{ }^{* *}$, and ${ }^{* * *}$ denote significance at 10 percent, 5 percent, and 1 percent respectively. 
Table 3. Sensitivity analysis of production function estimation in intensity form. (Dependent variable : $d \log y^{\mathrm{a}}$ )

\begin{tabular}{|c|c|c|c|c|c|c|c|c|}
\hline \multirow[b]{3}{*}{ Variables } & \multicolumn{2}{|c|}{$\begin{array}{c}\text { Sub-sample } \\
\text { with } \mu>1\end{array}$} & \multicolumn{2}{|c|}{$\begin{array}{l}\text { Sub-sample } \\
\text { with } \sigma^{2}>4\end{array}$} & \multicolumn{2}{|c|}{$\begin{array}{l}\text { Full sample with } \\
\text { labor quality } \\
\text { adjustments }\end{array}$} & \multicolumn{2}{|c|}{ 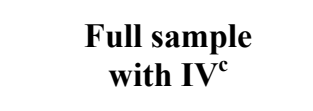 } \\
\hline & (i) & (ii) & (iii) & (iv) & (v) & (vi) & (vii) & (viii) \\
\hline & $\begin{array}{c}\text { 5-year } \\
\text { intervals }^{\mathrm{d}}\end{array}$ & $\begin{array}{c}\text { 10-year } \\
\text { intervals }^{\mathrm{d}}\end{array}$ & $\begin{array}{c}\text { 5-year } \\
\text { intervals }^{\mathrm{d}}\end{array}$ & $\begin{array}{c}\text { 10-year } \\
\text { intervals }^{\mathrm{d}}\end{array}$ & $\begin{array}{c}\text { 5-year } \\
\text { intervals }^{\mathrm{d}}\end{array}$ & $\begin{array}{c}\text { 10-year } \\
\text { intervals }\end{array}$ & $\begin{array}{c}\text { 5-year } \\
\text { intervals }^{\mathrm{d}}\end{array}$ & $\begin{array}{c}\text { 10-year } \\
\text { intervals }^{\mathrm{d}}\end{array}$ \\
\hline \multirow[t]{2}{*}{ dlogk } & $0.438^{* * *}$ & $0.440^{* * *}$ & $0.432^{* * *}$ & $0.418^{* * *}$ & $0.429^{* * *}$ & $0.423^{* * *}$ & $0.328^{* * *}$ & $0.340^{* * *}$ \\
\hline & $(0.040)$ & $(0.049)$ & $(0.039)$ & $(0.047)$ & $(0.039)$ & $(0.045)$ & $(0.060)$ & $(0.091)$ \\
\hline \multirow[t]{2}{*}{$\mu$} & $0.214^{* *}$ & $0.207^{* *}$ & $0.224^{* * *}$ & $0.231^{* * *}$ & $0.267^{* * *}$ & $0.260^{* * *}$ & $0.216^{* * *}$ & $0.193^{* *}$ \\
\hline & $(0.085)$ & $(0.088)$ & $(0.084)$ & $(0.088)$ & $(0.084)$ & $(0.087)$ & $(0.084)$ & $(0.090)$ \\
\hline \multirow[t]{2}{*}{$\sigma^{2}$} & $0.065^{* *}$ & $0.076^{* *}$ & $0.070^{* * *}$ & $0.083^{* * *}$ & $0.089^{* * *}$ & $0.094^{* * *}$ & $0.077^{* * *}$ & $0.076^{* *}$ \\
\hline & $(0.028)$ & $(0.032)$ & $(0.027)$ & $(0.032)$ & $(0.025)$ & $(0.028)$ & $(0.026)$ & $(0.030)$ \\
\hline \multirow[t]{2}{*}{$\log \left(A_{\delta}\left(\overline{A_{0}}\right)\right.$} & -0.398 & -0.358 & -0.403 & -0.407 & $-0.497^{* *}$ & $-0.480^{*}$ & $-0.438^{*}$ & -0.320 \\
\hline & $(0.247)$ & $(0.261)$ & $(0.248)$ & $(0.266)$ & $(0.244)$ & $(0.260)$ & $(0.246)$ & $(0.253)$ \\
\hline $\mathbf{R}^{2}$ & 0.363 & 0.483 & 0.359 & 0.470 & 0.366 & 0.488 & 0.373 & 0.461 \\
\hline Adjusted $\mathbf{R}^{2}$ & 0.351 & 0.470 & 0.348 & 0.457 & 0.356 & 0.476 & 0.362 & 0.447 \\
\hline $\begin{array}{l}\text { Number of } \\
\text { Observations }\end{array}$ & 494 & 248 & 508 & 253 & 540 & 268 & 505 & 240 \\
\hline $\begin{array}{l}\text { Number of } \\
\text { Countries }\end{array}$ & 91 & 91 & 92 & 91 & 94 & 94 & 93 & 93 \\
\hline
\end{tabular}

${ }^{\mathrm{a}} d \log X$ is $100 *\left(\log X_{t}-\log X_{t-\mathrm{T}}\right) / T(T=5$ or 10$)$ which is average annual growth rates of $X$ for T-year intervals in percentages. $y, k, \mu$, and $\sigma^{2}$ are GDP per worker, physical capital per worker, average index of human capital, and dispersion index of human capital, respectively. Human capital indices are the averages of the initial and terminal year values for each T-year interval. $A_{0} / \bar{A}_{0}$ is the average ratio of GDP per capita relative to that of the U.S. during the five years prior to the initial year of respective intervals. All estimates are ordinary least squares estimates and the numbers in the parentheses are White-heteroscedastic consistent standard errors. All models include unreported time-specific constants.

${ }^{\mathrm{b}}$ Labor quality was adjusted by augmenting labor with educational attainment data based on equation (16).

${ }^{\mathrm{c}}$ Instrumental variables (IV) method with White-heteroscedastic consistent standard errors. The list of instruments includes time-specific constants, regional dummies, catch-up variable, 5-year lags of average and dispersion indices of human capital, and 5-year log differences of the following variables: arable land per person, life expectancy at birth, male population, female population, fertility rate, cotton price relative to wheat price, oil price relative to wheat price, iron price relative to wheat price, world population, 5-year lags of physical capital, and labor.

${ }^{\mathrm{d}} 5$-year interval regressions are based on a pooled data set using the following 5-year interval data: 1965-70, 1970$75,1975-80,1980-85,1985-90$, and 1990-95. 10-year interval regressions are based on a pooled data set using the following 10-year interval data: 1965-75, 1975-85, and 1985-95.

${ }^{*}, * *$, and ${ }^{* * *}$ denote significance at 10 percent, 5 percent, and 1 percent respectively. 
Table 4. Production function estimation in original form. (Dependent variable : $\operatorname{dlog} Y^{\mathrm{a}}$ )

\begin{tabular}{|c|c|c|c|c|c|c|}
\hline \multirow[b]{3}{*}{ Variables } & \multicolumn{3}{|c|}{$\begin{array}{l}\text { 5-year interval } \\
\text { regressions }\end{array}$} & \multicolumn{3}{|c|}{$\begin{array}{l}\text { 10-year interval } \\
\text { regressions }\end{array}$} \\
\hline & (i) & (ii) & (iii) & (iv) & (v) & (vi) \\
\hline & OLS & $\mathbf{I V}^{\mathbf{c}}$ & $\mathbf{I V}^{\mathbf{c}}$ & OLS & $\mathbf{I} \mathbf{V}^{\mathbf{c}}$ & $\mathbf{I} \mathbf{V}^{\mathbf{c}}$ \\
\hline \multirow[t]{2}{*}{$d \operatorname{dog} K$} & $0.369^{* * *}$ & $0.296^{* * *}$ & $0.258^{* * *}$ & $0.367^{* * *}$ & $0.317^{* * *}$ & $0.272^{* *}$ \\
\hline & $(0.041)$ & $(0.062)$ & $(0.071)$ & $(0.044)$ & $(0.093)$ & $(0.115)$ \\
\hline \multirow[t]{2}{*}{$d \log L$} & 0.149 & $0.501^{* * *}$ & $0.531^{* * *}$ & 0.076 & $0.413^{* *}$ & $0.439^{* * *}$ \\
\hline & $(0.092)$ & $(0.179)$ & $(0.178)$ & $(0.116)$ & $(0.166)$ & $(0.166)$ \\
\hline \multirow[t]{2}{*}{$\mu$} & $0.200^{* * *}$ & $0.188^{* *}$ & $0.172^{* *}$ & $0.178^{* *}$ & $0.153^{*}$ & $0.141^{*}$ \\
\hline & $(0.078)$ & $(0.080)$ & $(0.079)$ & $(0.077)$ & $(0.081)$ & $(0.078)$ \\
\hline \multirow[t]{2}{*}{$\sigma^{2}$} & $0.125^{* * *}$ & $0.093^{* * *}$ & $0.078^{* * *}$ & $0.137^{* * *}$ & $0.096^{* * *}$ & $0.085^{* * *}$ \\
\hline & $(0.025)$ & $(0.028)$ & $(0.028)$ & $(0.027)$ & $(0.031)$ & $(0.030)$ \\
\hline \multirow[t]{2}{*}{$\log \left(A_{0} / \overline{A_{0}}\right)$} & $-0.700^{* * *}$ & $-0.525^{*}$ & $-0.717^{* *}$ & $-0.711^{* * *}$ & -0.429 & $-0.602^{* *}$ \\
\hline & $(0.244)$ & $(0.270)$ & $(0.280)$ & $(0.241)$ & $(0.264)$ & $(0.302)$ \\
\hline \multicolumn{7}{|c|}{ Regional constants $^{d}$} \\
\hline \multirow[t]{2}{*}{ Latin America } & & & $-0.622^{*}$ & & & -0.471 \\
\hline & & & $(0.353)$ & & & $(0.377)$ \\
\hline \multirow[t]{2}{*}{ Sub-Saharan } & & & $-1.068^{* *}$ & & & -0.898 \\
\hline & & & $(0.456)$ & & & $(0.582)$ \\
\hline $\mathbf{R}^{2}$ & 0.342 & 0.314 & 0.313 & 0.477 & 0.395 & 0.394 \\
\hline Adjusted $\mathbf{R}^{2}$ & 0.329 & 0.301 & 0.296 & 0.463 & 0.377 & 0.371 \\
\hline $\begin{array}{l}\text { Number of } \\
\text { Observation }\end{array}$ & 540 & 505 & 505 & 268 & 240 & 240 \\
\hline $\begin{array}{l}\text { Number of } \\
\text { Countries }\end{array}$ & 94 & 93 & 93 & 94 & 93 & 93 \\
\hline
\end{tabular}

${ }^{\text {a }} d \log X$ is $100 *\left(\log X_{t}-\log X_{t-T}\right) / T(T=5$ or 10$)$ which is average annual growth rates of $X$ for T-year intervals in percentages. $Y, K, L, \mu$, and $\sigma^{2}$ are GDP, physical capital, labor, average index of human capital, and dispersion index of human capital, respectively. Human capital indices are the averages of the initial and terminal year values for each T-year interval. $A_{0} / \bar{A}_{0}$ is the average ratio of GDP per capita relative to that of the U.S. during the five years prior to the initial year of respective intervals. All estimates are ordinary least squares estimates and the numbers in the parentheses are White-heteroscedastic consistent standard errors. All models include unreported time-specific constants.

${ }^{\mathrm{b}} 5$-year interval regressions are based on a pooled data set using the following 5-year interval data: 1965-70, $1970-75,1975-80,1980-85,1985-90$, and 1990-95. 10-year interval regressions are based on a pooled data set using the following 10-year interval data: 1965-75, 1975-85, and 1985-95.

${ }^{\mathrm{c}}$ Instrumental variables (IV) method with White-heteroscedastic consistent standard errors. The list of instruments includes time-specific constants, regional dummies, catch-up variable, 5-year lags of average and dispersion indices of human capital, and 5-year log differences of the following variables: arable land per person, life expectancy at birth, male population, female population, fertility rate, cotton price relative to wheat price, oil price relative to wheat price, iron price relative to wheat price, world population, 5-year lags of physical capital, and labor.

${ }^{\mathrm{d}}$ Regional constants are one for countries within each region and zero for the rest.

${ }^{*},{ }^{* *}$, and ${ }^{* * *}$ denote significance at 10 percent, 5 percent and 1 percent respectively. 
Table 5. Relationship between average index and dispersion index of human capital ${ }^{\mathrm{a}}$

\begin{tabular}{|c|c|c|c|c|c|c|c|}
\hline \multirow[b]{3}{*}{$\begin{array}{l}\text { Dependent } \\
\text { Variable: }\end{array}$} & \multicolumn{3}{|c|}{ Data set from Ram (1990) } & \multicolumn{4}{|c|}{ Data set from this study } \\
\hline & (i) & (ii) & (iii) & (iv) & (v) & (vi) & (vii) \\
\hline & $\begin{array}{c}\text { Standard } \\
\text { deviation } \\
\sigma \\
\end{array}$ & $\begin{array}{c}\text { Standard } \\
\text { deviation } \\
\sigma \\
\end{array}$ & $\begin{array}{c}\text { Variance } \\
\sigma^{2}\end{array}$ & $\begin{array}{c}\text { Standard } \\
\text { deviation } \\
\sigma \\
\end{array}$ & $\begin{array}{c}\text { Variance } \\
\sigma^{2}\end{array}$ & $\begin{array}{c}\text { Variance } \\
\sigma^{2}\end{array}$ & $\begin{array}{c}\text { Variance } \\
\sigma^{2}\end{array}$ \\
\hline Sample: & Full sample & Full sample & Full sample & Full sample & $\begin{array}{c}\text { Full } \\
\text { sample }\end{array}$ & $(\mu>1)$ & $\left(\sigma^{2}>4\right)$ \\
\hline Constant & & $\begin{array}{l}2.185^{* * *} \\
(0.253)\end{array}$ & & & & & \\
\hline$\mu$ & $\begin{array}{l}1.367^{* * *} \\
(0.045)\end{array}$ & $\begin{array}{l}0.666^{* * *} \\
(0.088)\end{array}$ & $\begin{array}{l}5.873^{* * * *} \\
(0.255)\end{array}$ & $\begin{array}{l}1.447^{* * *} \\
(0.020)\end{array}$ & $\begin{array}{l}5.587^{* * *} \\
(0.104)\end{array}$ & $\begin{array}{l}5.554^{* * *} \\
(0.110)\end{array}$ & $\begin{array}{l}5.558^{* * *} \\
(0.110)\end{array}$ \\
\hline$\mu^{2}$ & $\begin{array}{c}-0.101^{* * *} \\
(0.005)\end{array}$ & $\begin{array}{c}-0.053^{* * *} \\
(0.007)\end{array}$ & $\begin{array}{c}-0.454^{* * *} \\
(0.028)\end{array}$ & $\begin{array}{c}-0.111^{* * *} \\
(0.003)\end{array}$ & $\begin{array}{c}-0.412^{* * *} \\
(0.013)\end{array}$ & $\begin{array}{c}-0.408^{* * *} \\
(0.014)\end{array}$ & $\begin{array}{c}-0.409^{* * *} \\
(0.014)\end{array}$ \\
\hline Adjusted $\mathbf{R}^{2}$ & 0.366 & 0.399 & 0.365 & 0.559 & 0.491 & 0.327 & 0.314 \\
\hline Observations & 94 & 94 & 94 & 727 & 727 & 655 & 651 \\
\hline
\end{tabular}

${ }^{a} \mu$ and $\mu^{2}$ are mean and mean squared index of schooling years, respectively. All estimates are ordinary least squares estimates and the numbers in the parentheses are standard errors. ${ }^{*},{ }^{* *}$, and ${ }^{* * *}$ denote significance at 10 percent, 5 percent and 1 percent respectively. 
